\title{
O CUIDADO DE ENFERMAGEM A VÍTIMAS DE VIOLÊNCIA DOMÉSTICA
}

\author{
Maria Isabel Raimondo Ferraz ${ }^{1}$, Maria Ribeiro Lacerda², Liliana Maria Labronici³ ${ }^{3}$ Mariluci Alves Maftum4, Maria Lúcia
}

Raimondo ${ }^{5}$

\begin{abstract}
RESUMO: A violência é um fenômeno que atinge todas as classes sociais no mundo e acomete crianças, adolescentes, adultos e idosos. Este artigo tem como objetivo realizar reflexões a respeito da atuação do enfermeiro no cuidado prestado às mulheres vítimas de violência com vistas à estabelecer uma relação de cuidado. Praticada contra a mulher, a violência é caracterizada como doméstica e intrafamiliar e definida como violência de gênero devido às relações de submissão da mulher na sociedade. Cuidar destas vítimas é um desafio para os profissionais de saúde que em sua maioria podem possuir dúvidas, uma vez que não existe um modelo estruturado de como fazê-lo. Entretanto, existem algumas recomendações que acabam por representar linhas gerais para a atuação desses profissionais. O cuidado deve ser planejado para promover segurança, acolhimento, respeito e satisfação das necessidades individuais e, isto, será possível se for estabelecida uma relação de cuidado entre profissional e cliente.
\end{abstract}

PALAVRAS-CHAVE: Violência doméstica; Violência contra a mulher; Cuidados de enfermagem.

\section{THE NURSING CARE TO THE VICTIMS OF DOMESTIC VIOLENCE}

ABSTRACT: Violence is a phenomenon that affects all social classes in the world and affects children, adolescents, adults and elderly. This article aims to hold discussions about the role of nurses in the assistance provided to women victims of violence in order to establish a caring relationship. Practiced against women, violence is characterized as domestic and intrafamily and defined as violence of gender due to the submissive relationships of women in society. Taking care of these victims is a challenge for health professionals once the majority may have doubts on how to perform it, because there is no structured model of how to do it. However there are some recommendations that will ultimately represent guidelines for these professionals' work. Care must be designed to promote security, hosting, respect and satisfaction of individual needs; and this will be possible if a caring relationship is established between the professional and client.

KEYWORDS: Domestic violence; Violence against women; Nursing care.

\section{EL CUIDADO DE ENFERMERÍAA LAS VÍCTIMAS DE LA VIOLENCIA DOMÉSTICA}

RESUMEN: La violencia es un fenómeno que afecta a todas las clases sociales en el mundo y acomete niños, adolescentes, adultos y ancianos. Este artículo tiene como objetivo realizar reflexiones al respecto de la actuación del enfermero en el cuidado prestado a las mujeres víctimas de violencia con el fin de establecer una relación de cuidado. Practicada contra la mujer, la violencia se caracteriza como doméstica e intrafamiliar y definida como violencia de género debido a las relaciones de sumisión de la mujer en la sociedad. Cuidar de estas víctimas es un desafío para los profesionales de la salud que en su mayoría puede tener dudas, una vez que no existe un modelo estructurado de cómo hacerlo. Sin embargo, existen algunas recomendaciones que acaban por representar líneas generales directrices para la actuación de estos profesionales. El cuidado debe ser planificado para promover seguridad, acogimiento, respeto y satisfacción de las necesidades individuales y, esto, será posible si se establece una relación de cuidado entre profesional y cliente.

PALABRAS CLAVE: Violencia doméstica; Violencia contra la mujer; Atención en Enfermería.

\footnotetext{
*Artigo a partir disciplina Enfermagem e sua Prática Profissional do Curso de Mestrado em Enfermagem do Programa de Pós-Graduação em Enfermagem da Universidade Federal do Paraná-UFPR, no ano de 2008.

${ }^{1}$ Enfermeira. Docente da Universidade Estadual do Centro Oeste-UNICENTRO. Mestre em Enfermagem pelo Programa de PósGraduação em Enfermagem da UFPR. Membro do Grupo de Estudos Multiprofissional em Saúde do Adulto-GEMSA. Membro do Núcleo de Estudos e Pesquisa Sobre Violência Urbana-NEVUH-UNICENTRO.

${ }^{2}$ Enfermeira. Doutora em Enfermagem. Professora Adjunto do Departamento de Enfermagem da UFPR. Coordenadora do Núcleo de Estudos, Pesquisa e Extensão em Cuidado humano de Enfermagem-NEPECHE-UFPR. Coordenadora do Programa de Pós-Graduação em Enfermagem da UFPR.

${ }^{3}$ Enfermeira. Doutora em Enfermagem. Professora Adjunto do Departamento de Enfermagem e do Curso de Mestrado em Enfermagem da UFPR. Líder do GEMSA.

${ }^{4}$ Enfermeira. Doutora em Enfermagem. Professora Adjunto do Departamento de Enfermagem e do Curso de Mestrado em Enfermagem da UFPR. Membro do GEMSA.

${ }^{5}$ Enfermeira. Docente da UNICENTRO. Mestranda em Enfermagem pelo Programa de Pós-Graduação em Enfermagem da UFPR. Membro do GEMSA. Membro do NEVUH-UNICENTRO.
}

Autor correspondente:

Liliana Maria Labronici

Universidade Federal do Paraná

Rua Padre Camargo, 120 - 80060-240 - Curitiba-PR, Brasil

Recebido: 11/09/09

E-mail: lililabronici@yahoo.com.br

Aprovado: 03/11/09 


\section{INTRODUÇÃO}

O cuidado de enfermagem às vítimas de violência deve ser planejado para promover segurança, acolhimento, respeito e satisfação das suas necessidades individuais. Refletir sobre o seu planejamento, pautado nos instrumentos básicos de enfermagem, nas políticas públicas de saúde e na legislação vigente é fundamental para a proteção das vítimas e prevenção de agravos futuros.

Como fenômeno que atinge todas as classes sociais, etnias, religiões e culturas, a violência ocorre em populações de diferentes níveis de desenvolvimento social e econômico. Violência é definida pela Organização Mundial da Saúde-OMS como o uso da força física, do poder real ou ameaça, praticado contra si ou contra outra pessoa, ou ainda, contra um grupo ou uma comunidade, que resulte ou tenha possibilidade de resultar em lesão, morte, dano psicológico, deficiência de desenvolvimento ou privação. É compreendida também como uma violação dos direitos do ser humano, uma vez que é um meio aplicado para coagir ou submeter outra pessoa ao domínio sem seu consentimento ${ }^{(1)}$.

O drama da violência faz parte do cotidiano das cidades, do país e do mundo, é banalizado e percebido pela sociedade como algo que naturalmente faz parte da $\operatorname{vida}^{(1)}$. Por ser um fenômeno antigo, porém silenciado ao longo da história, a violência somente passou a ser pesquisada no Brasil na década de 1980. Essas pesquisas auxiliam na denúncia do impacto que esse agravo provoca na população. O resultado das várias manifestações de violência se estende ao trânsito, ao trabalho, às relações familiares, interpessoais e ao convívio doméstico ${ }^{(2)}$. Dentre as vítimas da violência doméstica estão as mulheres agredidas por seus companheiros, fato que na maioria das vezes ocorre dentro de seus próprios lares, demostrando que o tema deve ser objeto de estudos.

Ressalta-se que no Brasil, atualmente, a violência contra a mulher é tipificada como crime, com a finalidade de proteger as vítimas e punir os agressores, bem como, reduzir os índices destes agravos $^{(3)}$. Objetivando garantir os direitos da mulher na sociedade, foi sancionada, pelo Presidente da República, a Lei ${ }^{\circ} 11.340$, de 7 de agosto de 2006, conhecida como Lei Maria da Penha, que entrou em vigor em 22 de setembro do mesmo ano. De acordo com a referida Lei, ações de saúde precisam ser planejadas e implementadas, com vistas a prestar cuidado às vítimas e reduzir os índices de criminalidade em nosso país ${ }^{(4)}$.

Atualmente, a violência é tratada como um problema de saúde e deve ser objeto de estudo devido ao impacto causado na vida das pessoas e nos investimentos aplicados pelos governantes em todo o mundo para reduzir os índices de criminalidade. Estima-se que mundialmente, pelo menos uma em cada três mulheres já foi espancada, coagida ao sexo ou sofreu alguma forma de abuso durante sua vida ${ }^{(5)}$.

Dentre as diversificadas formas de violência contra a mulher, neste estudo, escolhemos fazer uma reflexão a respeito da violência doméstica e intrafamiliar. A violência doméstica ocorre no ambiente doméstico, nas relações entre pessoas da família e envolve homens, mulheres, pais, mães e filhos, jovens, idosos e portadores de deficiência. A violência doméstica pode ser praticada por empregados, agregados, pessoas que conhecem as vítimas e que frequentam diariamente ou esporadicamente o domicílio $^{(6)}$. Diferencia-se da intrafamiliar porque a violência doméstica inclui como agressores outras pessoas conhecidas sem parentesco ${ }^{(1)}$.

A violência intrafamiliar pode ocorrer dentro ou fora de casa, porém é praticada somente pelos membros da família com função parental que mantenham relação de poder para com as vítimas ${ }^{(2)}$. Independente da faixa etária, as vítimas podem sofrer espancamentos, humilhações, ofensas sendo que as mulheres são constantemente o alvo principal e os agressores aproveitam de sua vulnerabilidade para espancá-las e humilhá-las ${ }^{(1)}$.

Não existe uma causa única para que ocorra a violência doméstica, motivo pelo qual se configura como problema complexo desencadeado por uma multiplicidade de fatores. Esses podem contribuir para sua prática (individual, relacional e social), independente do sexo, idade, raça, etnia, educação, cultura, situação socioeconômica, profissão, religião, capacidades físicas ou mentais. Isso amplia o número de pessoas que em qualquer período de suas vidas podem estar vulneráveis à violência( ${ }^{(2)}$.

Os índices de violência doméstica devem ser estudados, conhecidos e abordados pelos profissionais das esferas jurídica, policial, psicossocial e de saúde, pois as vítimas necessitam de cuidado devido ao seu sofrimento e adoecimento(5). Também é necessário considerar que a participação do serviço social é fundamental neste processo.

Instigar a reflexão sobre o cuidado das vítimas 
de violência doméstica e intrafamiliar é necessário, pois inexiste um modelo estruturado para realizá-lo. O que se percebe na prática são profissionais da área de saúde com dificuldade em lidar com essas vítimas. $\mathrm{O}$ enfermeiro como integrante da equipe de saúde deve estar capacitado para perceber, enfrentar o problema e cuidar com responsabilidade. Assim, tem-se neste artigo o objetivo de realizar reflexão a respeito da atuação do enfermeiro no cuidado prestado às vítimas de violência doméstica com vistas à estabelecer uma relação de cuidado.

\section{A COMPLEXIDADE DO FENÔMENO VIOLÊNCIA E O CUIDADO DE ENFERMAGEM}

A violência é um fenômeno social e histórico de conceituação complexa, que envolve eventos de natureza diversa, relacionados às estruturas sociais, econômicas, políticas, culturais e comportamentais, que muitas vezes legitimam e fundamentam atos violentos contra as pessoas ${ }^{(7)}$.

A mulher pode ser vítima de violência física, psicológica, sexual, moral e patrimonial, portanto, ao abordar esse tema, se faz importante compreender suas definições ${ }^{(4)}$, bem como discorrer sobre a violência de gênero. Neste sentido, o termo gênero facilita a percepção das desigualdades sociais e econômicas existentes entre homens e mulheres, que se deve à discriminação histórica contra estas.

A expressão violência de gênero deve ser entendida como uma relação de poder e dominação dos homens e de submissão das mulheres, que externa os papéis impostos historicamente a ambos.

Violência contra a mulher é definida como aquela praticada contra a pessoa do sexo feminino, simplesmente pela condição de mulher, com a finalidade de intimidá-la para que o agressor exerça o papel de dominador e disciplinador ${ }^{(1)}$. É um problema de saúde pública e uma violação aos direitos humanos.

Estima-se que o problema cause mais mortes de mulheres do que o câncer, a malária, os acidentes de trânsito e as guerras ${ }^{(8)}$. Por ser tratado como um problema de saúde pública, cada vez mais é abordado pelos profissionais da área. Esses podem se sentir pouco preparados para oferecer atenção que cause impacto efetivo na saúde das vítimas. As dificuldades para cuidar das vítimas podem estar relacionadas com a formação acadêmica, na qual raramente são incluídos assuntos com produção de conhecimento técnico e específico sobre o tema violência ${ }^{(9)}$.
Atualmente, o cuidado das mulheres que sofreram violência sexual em sua maioria, ainda está sob a responsabilidade da polícia ou dos serviços de emergência, os quais também podem possuir limitações para responder às reais necessidades das vítimas. $\mathrm{O}$ despreparo profissional para cuidar destas mulheres se reflete em pré-conceitos como o de culpar a vítima, desestimulando-a a denunciar o agressor. Muitas vezes a perseguição ao agressor está em primeiro plano e a atenção às necessidades da vítima fica limitada ao tratamento de eventuais traumas sofridos ${ }^{(10)}$. A falta ou a pouca resolutividade no desenvolvimento do cuidado torna o problema ainda mais grave, pois essas atitudes tendem a afastar as vítimas do serviço de saúde, inibe a denúncia e fortalece o conceito de invisibilidade do problema.

Mesmo que os dados sobre a violência contra a mulher registrados pelas Delegacias da Mulher sejam surpreendentes, é preciso atentar que esses números não retratam com fidedignidade a realidade, haja vista que é comprovado que existe subnotificação, pois somente em torno de $10 \%$ das mulheres violentadas registram a ocorrência nas Delegacias de Polícia ${ }^{(11)}$. Porquanto, é importante que a vítima seja encorajada a fazer o registro da ocorrência nos órgãos competentes.

É preciso atender todas as usuárias que comparecem às unidades de emergência com atenção voltada não somente para as lesões físicas, mas também perscrutar a possibilidade da ocorrência de violência, uma vez que esta, ainda, pode não estar incorporada pelos profissionais de saúde como um problema de saúde e igualmente não identificada como causa de traumas apresentados pelas vítimas ${ }^{(12)}$.

Os profissionais de saúde devem estar atentos às mulheres que procuram os serviços com manifestações clínicas de violência, agudas ou crônicas, físicas, mentais ou por problemas sociais. Lesões físicas agudas normalmente são oriundas de agressões causadas por uso de armas, socos, pontapés, tentativas de estrangulamento ou queimaduras e, os casos mais graves são os que apresentam faturas nos ossos da face, costelas, mãos, braços ou pernas. As manifestações clínicas crônicas podem ser decorrentes de agressões sexuais que podem causar doenças sexualmente transmissíveis, infecções urinárias, vaginais e gravidez indesejada. Podem surgir posteriormente à agressão e devem ser objeto de atenção durante a realização dos cuidados prestados ${ }^{(6)}$.

O Ministério da Saúde, através das políticas de saúde, faz orientações para a prática profissional e 
refere que a violência doméstica pode ser repetitiva e deve ser detectada precocemente com prevenção de agravos futuros. As vítimas devem ser orientadas sobre a violência, seu curso e os recursos existentes na comunidade, como grupos de autoajuda, cuidado de enfermagem, atendimento médico, psicológico, do serviço social e de outros membros da equipe multiprofissional, com vistas a prevenir novos episódios ${ }^{(6)}$.

Existem alguns passos que podem integrar as ações de cuidado de enfermagem e dos demais profissionais de saúde, os quais devem envolver o acolhimento e a possibilidade de apoio por parte da equipe; auxiliar a vítima a estabelecer vínculo de confiança individual e institucional para poder avaliar o histórico da violência e as possibilidades de mobilizar recursos sociais e familiares; dialogar com a mulher sobre as opções de lidar com o problema, permitindolhe fazer escolhas e fortalecer sua autoestima; apoiar a vítima que deseja fazer registro policial do fato; fazer encaminhamentos à outros órgãos competentes quando necessário, Delegacias da Mulher, Instituto MédicoLegal; incentivar a construção de vínculo com as redes de assistência, acompanhamento, proteção e redes de apoio; encaminhar para atendimento clínico os casos de lesões graves, com necessidade de reabilitação, que não puderem ser atendidos na unidade; sugerir à vítima atendimento para o casal ou família no caso de continuidade da relação; propor acompanhamento psicológico; fazer visitas domiciliares constantes para cuidar e acompanhar o caso ${ }^{(6: 50-1)}$.

Os passos anteriormente citados são fortalecidos pela Lei $\mathrm{n}^{\circ} 11.340$, que estabelece que o Estado e municípios têm o dever de assegurar os direitos à saúde da mulher com planejamento e implementação de redes de apoio, com implementação de programas de saúde para cuidar das vítimas e reduzir os índices de criminalidade em nosso país ${ }^{(4)}$.

Cuidar do ser humano em sua totalidade inclui elaborar e aplicar medidas de promoção e prevenção que podem ser potencializadas pela educação permanente, com esclarecimentos sobre os direitos e prerrogativas das vítimas. Também, assegurar que toda mulher, independente de classe, raça, etnia, religião, orientação sexual, renda, cultura, nível educacional, idade e religião, goze dos direitos fundamentais e inerentes à pessoa humana ${ }^{(13)}$.

Como um processo de desenvolvimento e crescimento, o cuidado deve ser planejado para respeitar crenças e valores em relação à vida, morte, saúde, doença e cura ${ }^{(14)}$. O cuidar exige do enfermeiro a utilização de instrumentos fundamentais para o exercício profissional, os quais são meios para que o cuidador atinja os objetivos propostos. Esses instrumentos envolvem a observação, o cuidado emocional, o toque terapêutico, o corpo, o bom senso, a liderança, o caráter humanitário, a solidariedade, a sensibilidade, a técnica, a relação educativa e as dimensões psicossocial e psicoespiritual $^{(15-16)}$. O emprego dos instrumentos básicos de enfermagem, além de se constituir no caminho para estabelecer uma relação de cuidado, permite que a vítima de violência se sinta cuidada e consiga expor e perceber os motivos que a levaram a esta condição. Eles servem de base para encontrar alternativas para enfrentar positivamente o problema.

Para cuidar é necessário o estabelecimento de uma relação de cuidado em que é preciso existir um processo interativo entre o cuidador e a pessoa que está sendo cuidada. Para que esta relação aconteça é necessário intencionalidade, disponibilidade, receptividade, confiança e aceitação promovendo o crescimento de ambos, profissional e paciente ${ }^{(14)}$. Para cuidar é preciso conhecimento técnico-científico, habilidades e competência próprias da profissão, que favoreçam a percepção do ser humano nos aspectos biológico, psicológico, social e espiritual.

\section{CONSIDERAÇÕES FINAIS}

Na história da humanidade é possível perceber que a violência contra as mulheres sempre esteve presente em diferentes culturas, nas mais variadas formas, porque foram preparadas para estabelecer uma relação de sujeição e obediência para com seus companheiros.

O ambiente doméstico é o local em que mais se pratica violência contra as mulheres, isso faz parte do cotidiano nas cidades, no país e no mundo e a torna banalizada, percebida como algo que naturalmente faz parte da vida.

Os profissionais de saúde, em especial a enfermagem, estão em contato direto com a maioria das vítimas, pois é nos serviços de saúde que normalmente buscam ajuda e tratamento para seus males. Isso os deixa próximos, fornece a possibilidade de construir elos de confiança e permite reconstruir conceitos sobre a violência, com vistas a reduzir os índices deste agravo e mudar a realidade social.

Para que os profissionais da área de saúde reconheçam a violência e cuidem das vítimas com 
efetividade, é necessário que estejam capacitados para tal. Não existe um modelo para cuidar, porém, profissionais melhor preparados terão condições de estabelecer uma relação de cuidado que extrapole as ações técnicas com estabelecimento de vínculos de cuidado com o paciente. Ressalta-se que o processo de cuidar não ocorre isoladamente, mas por meio de intencionalidade, interação, disponibilidade e confiança entre profissional e paciente.

\section{REFERÊNCIAS}

1. Teles MAA, Melo M. O que é violência contra a mulher. São Paulo: Brasiliense; 2003.

2. Ministério da Saúde (BR). Política nacional de atenção integral à saúde da mulher: princípios e diretrizes. Brasília: Ministério da Saúde; 2004.

3. Porto PRF. Violência doméstica e familiar contra a mulher: Lei 11.340/06 - análise crítica e sistêmica. Porto Alegre: Livraria do Advogado; 2007.

4. Ministério da Saúde (BR). Epidemiologia e serviços de saúde. Revista do Sistema Único de Saúde. 2006;16(1):618.

5. Schraiber LB, Oliveira AFPL. O que devem saber os profissionais de saúde para promover os direitos e a saúde das mulheres em situação de violência doméstica. Rio Grande do Sul: Fundação Ford; 2006.

6. Ministério da Saúde (BR). Violência intrafamiliar: orientações para a prática em serviço. Brasília: Ministério da Saúde; 2002.

7. Malta DC, Lemos MSA, Silva MMA, Rodrigues EMS, Gazal-Carvalho C, Morais Neto OL. Iniciativas de vigilância e prevenção de acidentes e violência no contexto do Sistema Único de Saúde. Epidemiol Serv Saúde. 2007 Mar;16(1):45-55.

8. Schraiber LB, d'Oliveira AFPL, França-Junior I, Pinho AA. Violência contra a mulher: estudo em uma unidade de atenção primária à saúde. Rev Saúde Públ. 2002 Ago;36(4):470-7.

9. Faúndes A, Rosas CF, Bedone AJ, Orozco LT. Violência sexual: procedimentos indicados e seus resultados no atendimento de urgência de mulheres vítimas de estupro. Rev Bras Ginecol Obstet. 2006;28(2):126-35.

10. Dias MB. A Lei Maria da Penha na justiça: a efetividade da Lei 11.340/2006 de combate à violência doméstica e familiar contra a mulher. São Paulo: Revista dos Tribunais; 2007.

11. Leal SMC, Lopes MJM. Violência como objeto da assistência em um hospital de trauma: “o olhar” da enfermagem. Ciênc Saúde Col. 2005;10(2):419-31.

12. Hermann LM. Maria da Penha: lei com nome de mulher. São Paulo: Servanda; 2007.

13. Waldow VR. Cogitando sobre o cuidado humano. Cogitare Enferm. 1998 Jul/Dez;3(2):7-10.

14. Silva MBGM, Tonelli ALN, Lacerda MR. Instrumentos do cuidado humanizado de enfermagem: uma reflexão teórica. Cogitare Enferm. 2003 Jan/Jun;8(1):59-64.

15. Mayeroff M. A arte de servir ao próximo para servir a si mesmo. Rio de janeiro: Record; 1971.

16. Silva MBGM, Tonelli ALN, Lacerda MR. Instrumentos do cuidado humanizado de enfermagem: uma reflexão teórica. Cogitare Enferm. 2003 Jan/Jun;8(1):59-64. 